\title{
Profile of American tegumentary leishmaniasis in transmission areas in the state of Minas Gerais, Brazil, from 2007 to 2017
}

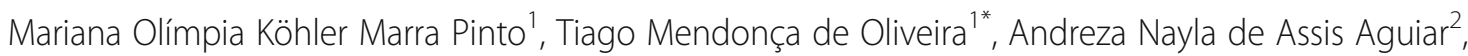
Paulo Eustáquio Marra Pinto ${ }^{2}$, David Soeiro Barbosa ${ }^{3}$, Soraia de Araújo Diniz ${ }^{4}$ and Marcos Xavier Silva ${ }^{1 *}$

\begin{abstract}
Background: American tegumentary leishmaniasis (ATL) is a widespread anthropozoonosis caused by protozoa of the genus Leishmania and is considered a serious public health problem. The aim of this study was to provide a descriptive analysis of confirmed ATL cases and evaluate the spatial distribution of ATL in high-risk transmission areas from the state of Minas Gerais, Brazil.

Methods: An ecological, analytical, and retrospective study of the confirmed cases of ATL in Minas Gerais from 2007 to 2017 was conducted. To characterize these cases, multiple correspondence analysis and georeferencing of the ATL prevalence rates in the municipalities were conducted based on variables obtained at Sistema Nacional de Agravos de Notificação and Instituto Brasileiro de Geografia e Estatística databases.

Results: There were 13,025 confirmed cases of ATL from 74.4\% (635) municipalities of Minas Gerais, corresponding to a prevalence rate of 66.5 cases for every 100,000 inhabitants. Males aged 20 to 59 years and individuals who attended elementary school were most affected with ATL. Multiple correspondence analysis presented an accumulated qui-squared value of $44.74 \%$, proving that there was a relationship between the variables, including ethnicity, age, pregnancy status, zone of infection, and number of cases.

Conclusion: We confirmed that ATL is endemic to Minas Gerais, and there is high risk of infection within the municipalities due to a high rate of parasite transmission. The occurrence of infection in children, pregnant women, and the indigenous population demonstrates the need for the government to expand social policies aimed at vulnerable groups.
\end{abstract}

Keywords: Cutaneous leishmaniasis, Epidemiology, Public health, Zoonoses

\section{Background}

American tegumentary leishmaniasis (ATL) is a widespread zoonotic disease that has a global impact [1]. It is caused by the protozoa of the genus Leishmania and is considered a serious public health problem [2]. Phlebotomine sand flies, such as Nyssomyia spp. and Lutzomyia spp., belonging to the family Psychodidae (subfamily Phlebotominae), act as vectors for Leishmania in the

\footnotetext{
*Correspondence: tiago0725@gmail.com; vetmarcosxavier@hotmail.com ${ }^{1}$ Preventive Veterinary Medicine Department, School of Veterinary, Federal University of Minas Gerais, Belo Horizonte 31270-901, Brazil

Full list of author information is available at the end of the article
}

Americas and play an important role in disease dissemination among humans and domestic animal reservoirs [3-5]. In Brazil and South America, the major agent causing ATL is the Leishmania (Viannia) braziliensis [6].

Recently, ATL has been reported in all Brazilian states, and its epidemiological pattern has gone through changes regarding its transmission, with the occurrence of peaks every five years [7]. From 2007 to 2017, 232,989 cases of ATL were reported in Brazil, with a mean prevalence of 118.39 cases annually for every 100,000 inhabitants.

(C) The Author(s). 2020 Open Access This article is distributed under the terms of the Creative Commons Attribution 4.0 International License (http://creativecommons.org/licenses/by/4.0/), which permits unrestricted use, distribution, and reproduction in any medium, provided you give appropriate credit to the original author(s) and the source, provide a link to the Creative Commons license, and indicate if changes were made. The Creative Commons Public Domain Dedication waiver (http://creativecommons.org/publicdomain/zero/1.0/) applies to the data made available in this article, unless otherwise stated. 
In the state of Minas Gerais, ATL was first reported in 1940, and its transmission has been reported from both rural and peri-urban areas [8]. Thus, the objective of the present study was to use descriptive analysis to characterize ATL cases from the state of Minas Gerais and demonstrate their spatial and temporal distribution from 2007 to 2017.

\section{Methods}

\section{Development of the study}

An ecological, analytical, and retrospective study of confirmed cases of ATL, which occurred between 2007 and 2017 in Minas Gerais, was conducted using the secondary database established by the Sistema de Informação de Agravos de Notificação (SINAN) and the Brazilian Institute of Geography and Statistics, also known as Instituto Brasileiro de Geografia e Estatística (IBGE).

\section{Location of the study}

The state of Minas Gerais is located in the southeastern region of Brazil and is divided into 853 municipalities. Its territorial area is $586,520.732 \mathrm{~km}^{2}$, and its vegetation is composed of $19.94 \%$ savannah, $10.33 \%$ Atlantic forest, and $3.48 \%$ caatinga; $33.8 \%$ of the total area is native forest $[9,10]$. According to the IBGE census conducted in 2010, Minas Gerais had a population of 19,597,330 inhabitants, corresponding to a population density of 33.41 inhabitants per $\mathrm{km}^{2}$ [9].

\section{Database}

A total of 635 municipalities in Minas Gerais, which reported confirmed cases of ATL were considered as analytical units, and epidemiological aspects that could characterize these cases were evaluated using data obtained from SINAN. Demographic variables, such as gender, age, education level, zone of infection, and ethnicity were evaluated, in addition to variables, such as pregnancy status, annual and monthly frequency of disease, and ATL confirmation criteria. These variables were dichotomized or categorized to perform a multiple correspondence analysis. An adaptation of the criteria presented by $[7,11]$ was used to classify the epidemiological condition of ATL cases from Minas Gerais, which considered the prevalence rate of each municipality positive for ATL. The number of ATL cases within each municipality was categorized as "low" for 1-20 cases, "moderate" for 21-50 cases, and "high" for 51-828 cases.

\section{Statistical analyses}

Multiple correspondence analysis of the data was performed using the software Stata 12.0 (Stata Statistical Software: Release 12. College Station, TX: StataCorp LP). Variables that comprised the correspondence model were selected using Pearson's chi-square test $(P \leq 0.05)$ and evaluated for possible associations between the number of cases and other variables using graphs, which were interpreted by evaluating the proximity of the variables under the category "number of cases." The intensity of association with values of cumulative inertia above $40 \%$ was considered [12].

For the epidemiological analysis of ATL from 2007 to 2017 in Minas Gerais, a control diagram was designed by calculating the mean, upper and lower limits, and standard deviation. By using this diagram, it was possible to evaluate the temporal evolution of the disease and detect possible alterations in its distribution pattern. The diagram data can be used to developing effective protective measures against the ATL [13].

\section{Georeferencing}

The prevalence rate of ATL in the municipalities, was calculated in a $95 \%$ confidence interval based on data obtained from SINAN, and a georeferencing map was constructed. The software QGIS 2.18.14 (QGIS Development Team, 2009, QGIS Geographic System, Open Source Geospatial Foundation) was used to map the spatial distribution of municipalities with prevalent infection using data for confirmed cases of ATL that occurred in Minas Gerais from 2007 to 2017 (Fig. 1). After the calculation of the prevalence rate, 20 municipalities were identified as having prevalent infection, with the highest number of cases observed in the state of Minas Gerais (Table 1).

\section{Results}

From 2007 to 2017, 13,025 confirmed cases of ATL from 74.4\% (635) municipalities of Minas Gerais (Fig. 1) were reported, corresponding to a prevalence rate of 66.5 cases for every 100,000 inhabitants. One third of these cases were reported from 15 municipalities evaluated in this study (Table 1). The municipalities of São João das Missões, São João do Pacuí, São Domingos das Dores, Varzelândia, and Januária had the highest prevalence rates of ATL. Data for Belo Horizonte, Teófilo Otoni, Montes Claros, Ipatinga, and Patos de Minas were included in the variable analysis owing to their importance as economic centers of the state and because they reported a moderate to high frequency of the disease.

A total of $90.65 \%$ cases were diagnosed using clinicallaboratory criteria, while $9.35 \%$ of cases were diagnosed using clinical-epidemiological criteria. Laboratory diagnosis involved immunological examinations, such as the Montenegro intradermoreaction, parasitological tests with direct visualization of the parasite, in vitro isolation and culture, in vivo isolation, and polymerase chain reaction. The clinical-epidemiological criteria for diagnosing cutaneous leishmaniasis were applied only to individuals without access to laboratory diagnostic services and with 


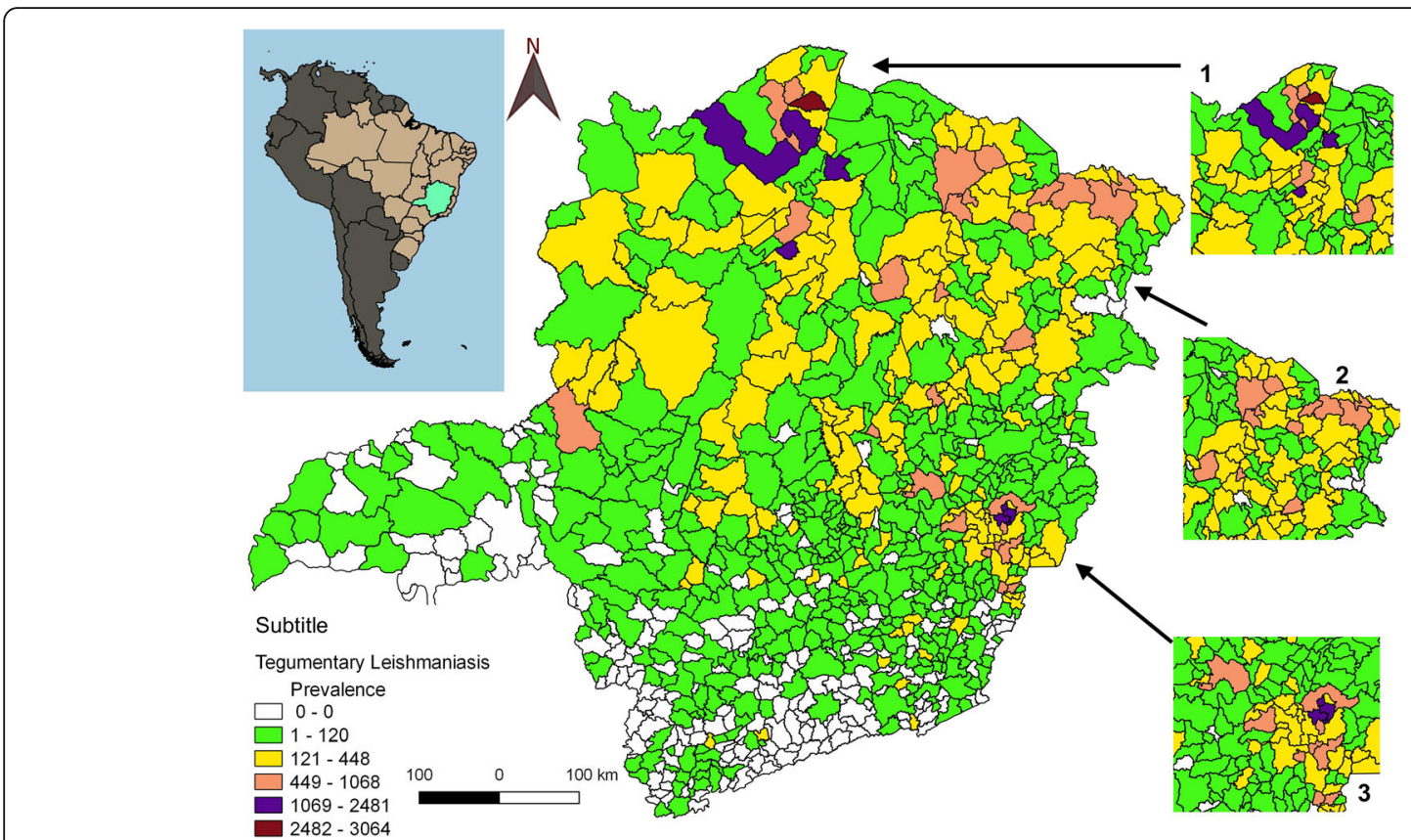

Fig. 1 Distribution of the ATL confirmed cases in Minas Gerais, Brazil from 2007 to 2017

Table 1 Cases of American tegumentary leishmaniasis (ATL) in areas with a high risk of transmission in Minas Gerais (2007 to 2017)

\begin{tabular}{|c|c|c|c|}
\hline Municipalities with reported cases & No. of cases & Population (2010) & Prevalence rate $^{*}$ \\
\hline São João das Missões & 359 & 11,715 & 3064.4 \\
\hline São João do Pacuí & 98 & 4066 & 2410.2 \\
\hline São Domingos das Dores & 86 & 5396 & 1593.8 \\
\hline Varzelândia & 273 & 19,126 & 1427.4 \\
\hline Januária & 828 & 65,464 & 1264.8 \\
\hline Ubaporanga & 138 & 12,040 & 1146.2 \\
\hline Imbé de Minas & 69 & 6412 & 1076.1 \\
\hline Simonésia & 187 & 18,302 & 1021.7 \\
\hline Piedade de Caratinga & 66 & 7101 & 929.4 \\
\hline Cachoeira de Pajeú & 68 & 8962 & 758.8 \\
\hline Novorizonte & 37 & 4953 & 747.0 \\
\hline Vermelho Novo & 35 & 4689 & 746.4 \\
\hline Rio Pardo de Minas & 216 & 29,075 & 742.9 \\
\hline Inhapim & 170 & 24,269 & 700.5 \\
\hline Cônego Marinho & 47 & 7089 & 663.0 \\
\hline Teófilo Otoni & 218 & 134,733 & 161.8 \\
\hline Montes Claros & 514 & 361,971 & 142.0 \\
\hline Ipatinga & 257 & 239,177 & 107.5 \\
\hline Patos de Minas & 147 & 138,836 & 105.9 \\
\hline Belo Horizonte & 221 & $2,375,444$ & 9.3 \\
\hline
\end{tabular}


residence, origin, or displacement to an area with confirmed cases.

When considering gender and age variables, male individuals $(60.21 \%)$ and adults aged 20 to 59 years $(56.89 \%)$ were seen to be the most affected. The education-level variable showed that approximately $36 \%$ of the cases reported in the highlighted municipalities, were those of individuals who had elementary schooling. However, $50 \%$ of notification forms did not include this information in these locations. Upon evaluating the role of ethnicity in disease prevalence, we verified that the individuals most affected by ATL were brown skinned (44.05\%). There were 24 cases of pregnant women with ATL, representing $0.59 \%$ of all forms of ATL notifications in high transmission areas (Table 2).

The prevalence of confirmed cases of ATL is highlighted in Fig. 1. A cluster can be observed in north Minas Gerais, Rio Doce (east), and Jequitinhonha valley. The southern and Mineiro Triangle regions presented low to moderate prevalence.

The control diagram describes the expected ATL case average in Minas Gerais from 2007 to 2017 and suggests

Table 2 American tegumentary leishmaniasis case description related to epidemiological and demographic variables from 2007 to 2017, Minas Gerais, Brazil

\begin{tabular}{|c|c|c|c|c|}
\hline Variable & n (MG scenario) & $\%$ & $\mathrm{n}$ (municipalities with highest prevalence rates*) & $\%$ \\
\hline \multicolumn{5}{|l|}{ Gender } \\
\hline Male & 7926 & 60.85 & 2429 & 60.21 \\
\hline Female & 5097 & 39.14 & 1605 & 39.79 \\
\hline Ignored & 2 & 0.01 & - & - \\
\hline \multicolumn{5}{|l|}{ Ethnicity } \\
\hline White & 4174 & 32.05 & 1024 & 25.38 \\
\hline Black & 1210 & 9.29 & 192 & 4.76 \\
\hline Yellow & 134 & 1.03 & 32 & 0.79 \\
\hline Brown & 5827 & 44.74 & 1777 & 44.05 \\
\hline Indigenous & 369 & 2.84 & 341 & 8.45 \\
\hline Ignored & 1311 & 10.05 & 679 & 16.83 \\
\hline \multicolumn{5}{|l|}{ Age range } \\
\hline Child (younger than 1-year-old) & 143 & 1.09 & 33 & 0.82 \\
\hline Child (1-14 years old) & 1817 & 13.95 & 730 & 18.10 \\
\hline Teenager (15-19years old) & 902 & 6.93 & 361 & 8.95 \\
\hline Adult (20-59 years old) & 7579 & 58.19 & 2295 & 56.89 \\
\hline Elderly (60 years old or older) & 2584 & 19.84 & 615 & 15.25 \\
\hline \multicolumn{5}{|l|}{ Education level } \\
\hline Illiterate & 705 & 5.41 & 138 & 3.42 \\
\hline Elementary school degree & 5685 & 43.65 & 1441 & 35.72 \\
\hline High school degree & 1293 & 9.93 & 319 & 7.91 \\
\hline Graduation degree & 312 & 2.39 & 109 & 2.70 \\
\hline Ignored / Not applied & 5030 & 38.62 & 2027 & 50.25 \\
\hline \multicolumn{5}{|l|}{ Pregnancy } \\
\hline Not applied & 12,518 & 96.11 & 3836 & 95.09 \\
\hline Yes & 79 & 0.60 & 24 & 0.59 \\
\hline Ignored & 428 & 3.29 & 174 & 4.31 \\
\hline \multicolumn{5}{|l|}{ Confirmation criteria } \\
\hline Clinical-laboratory & 11,023 & 84.63 & 3657 & 90.65 \\
\hline Clinical-epidemiological & 2002 & 15.37 & 377 & 9.35 \\
\hline TOTAL & 13,025 & 100.00 & 4034 & 100.00 \\
\hline
\end{tabular}

Subtitle: $(*)$ every 100,000 inhabitants

Ethnicity data is based on the IBGE demographic census, as shown on the website <https://educa.ibge.gov.br/jovens/conheca-o brasil/populacao/18319-cor-ou-raca.html> 
that Minas Gerais is an endemic location for the disease. Moreover, the average number of cases was slightly higher in the months when the temperature was warmer compared to the average number of cases during the colder months (Fig. 2).

The correspondence analysis plot, demonstrating the epidemiologic profile of ATL in Minas Gerais, presented an accumulated chi-squared value of $44.74 \%$, and the evaluated variables of the model have been highlighted by blue circles in Fig. 3. We observed that the number of case variables corresponded with variables, such as age, ethnicity, and education level, zone of infection, and pregnancy status. The associations among a set of variables, such as age, gender, ethnicity, zone of infection, and confirmation criteria was also verified.

We observed that municipalities with a moderate (21 to 50 ) to high (51 to 828) number of confirmed ATL cases were associated with the following characteristics: pregnancy, indigenous population, peri-urban zone, yellow-skinned individuals, and children younger than 1-year-old. Municipalities with a low number of ATL cases (1-20) were associated with characteristics, such as education level, age range, skin color (not black- or yellow- skinned), and non-indigenous origin. The confirmation criteria were not clinical and epidemiological, and the infection did not occur in peri-urban areas.

An association among brown skin, age 4 (60 years or older), female sex, infection in rural areas, and diagnosis made based on clinical-epidemiological criteria was also analyzed.

\section{Discussion}

In the last 11 years, 13,025 cases of ATL were confirmed in Minas Gerais, and the highest prevalence rate was observed in municipalities from the north of the state and from Rio Doce (east) and Jequitinhonha Valley. These regions are known as zones of low development and poverty and present significant diversity among the phlebotomine species. These features may be related to the dissemination of ATL to humans and domestic animals, which act as reservoirs, in these areas. In addition, anthropogenic factors are also determinants of disease maintenance [14-16].

We verified that the most effective confirmation criteria were those from the clinic and the laboratory. Confirmation of ATL using the clinical-epidemiological criteria provides important epidemiological information, as it identifies the parasite and may help in taking control measures against it. This result is in agreement with the Ministry of Health Guidance for Health Surveillance (2017) [7], which claims that the parasitological method for ATL diagnosis may be conducted before the onset of treatment, especially in cases where the clinical evolution is not ordinary and/or there is a bad response to treatment.

Analysis of data on the age and gender of patients with ATL in Minas Gerais revealed that males of working age were more susceptible to the disease, a finding that corroborates with those of previous reports [17, 18]. This might be because the occupations of males in this region, such as military occupation and construction, put them at a higher risk of being exposed to ATL vectors $[19,20]$.

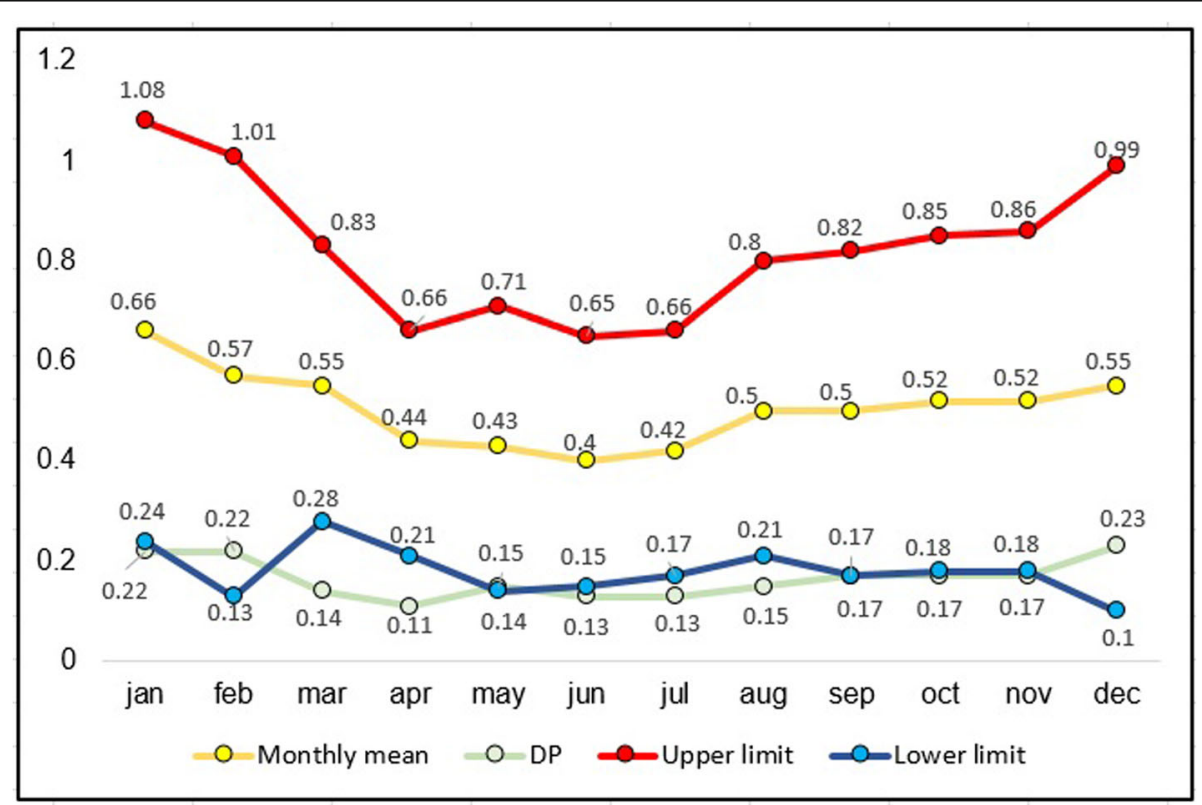

Fig. 2 Control diagram according to the monthly average frequency of ATL cases in Minas Gerais, from 2007 to 2017 


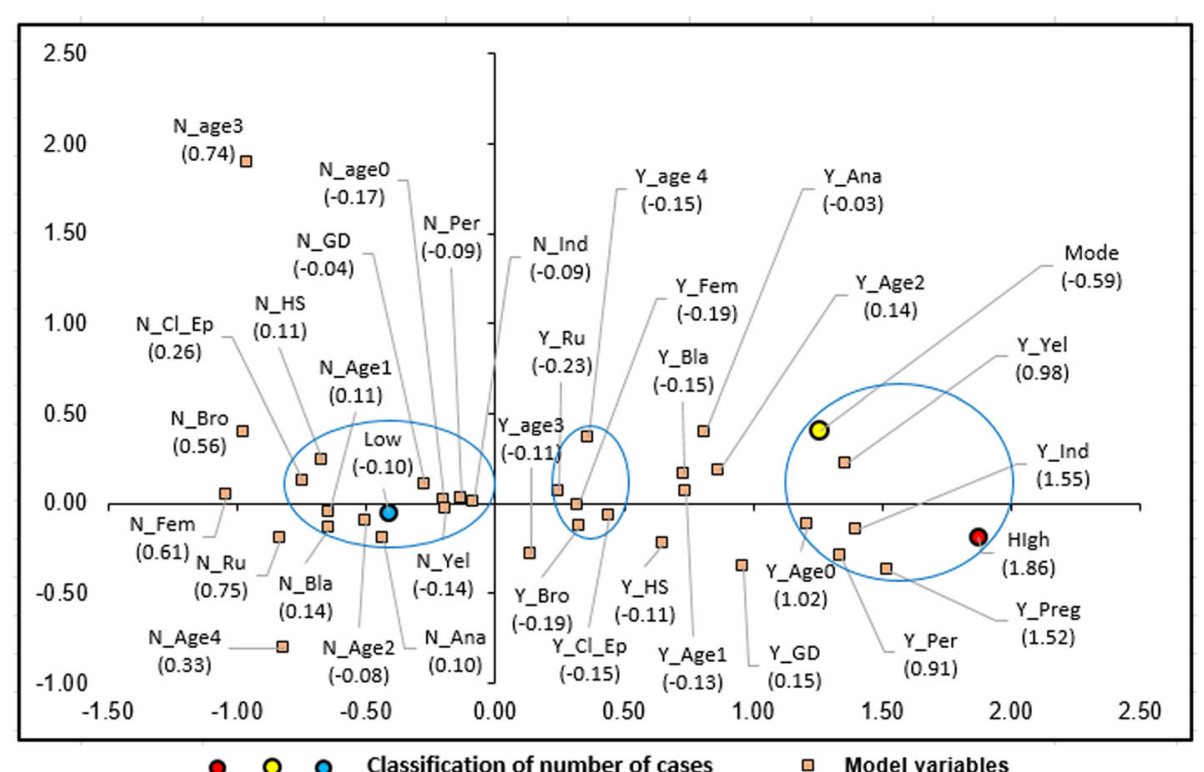

Fig. 3 Graphic of the Multiple Correspondence Analyses of the epidemiological of the ATL cases occurred between 2007 and 2017 in Minas Gerais, Brazil. Low: municipalities with low number of cases; Mode: municipalities with moderate number of cases; High: municipalities with high number of cases; N_Ana: not illiterate; Y_Ana: illiterate; N_HS: do not have high school degree; Y_HS: have high school degree; N_GD: do not have graduate degree; Y_GD: have graduate degree; N_Preg: not pregnant; Y_Preg: pregnant; N_Age0: not age 0 (younger than 1-year-old); Y_Age0: age 0 (younger than 1-year-old); N_Age1: not age 1 (1-14 year-old); Y_Age1: age 1 (1-14 years old); N_Age2: not age 2 (15-19 years old); Y_Age2: age 2 (15-19years old); N_Age3: not age 3 (20-59 years old); Y_Age3: age 3 (20-59years old); N_Age4: not age 4 (60 years old or older); Y_Age4: age 4 (60 years old or older); N_Cl_ep: not evaluated using clinical-epidemiological criteria; Y_Cl_ep: evaluated using clinicalepidemiological criteria; N_Bla: not black patients; Y_Bla: black patients; N_Yel: not yellow patients; Y_Yel: yellow patients; N_Bro: not brown patients; Y_Bro: brown patients; N_Ind: not Indian patients; Y_Ind: Indian patients; N_Fem: not female patients; Y_Fem: female patients; N_Per: not peri urban area; Y_Per: peri urban area; N_Ru: not rural area; $Y_{\_}$Ru: rural area

The low education level among most patients with ATL might be associated with a poor understanding of risk factors related to the disease. The occurrence of ignored notification forms this variable (50.25\%) might make it difficult to implement educational measures targeted to specific risk groups according to the degree of education. Additionally, the absence of educational level data makes it impossible to evaluate this criterion and is a limitation of this study.

Concerning the ethnicity of the patient, the ATL infection pattern agrees with the racial-ethnic characteristics of the Brazilian population demonstrated by IBGE (2010) [11]. According to IBGE, there is a larger brown skinned population in Brazil compared to the populations of other ethnicities. However, São João das Missões, a municipality located $663 \mathrm{~km}$ from the capital Belo Horizonte also has a strong presence of indigenous populations. There are a total of 33 villages occupied by the Xakriabá in Belo Horizonte [21]. In these villages, 359 cases of ATL were reported over a period of 11 years; 333 (92.8\%) occurred within the indigenous population. Moreover, this municipality presented the highest prevalence of ATL in Minas Gerais during the study period (3064.4 cases per 100,000 inhabitants). Thus, it is considered an area of high risk for the transmission of Leishmania (Fig. 1 and Fig. 3). The data demonstrated greater susceptibility to Leishmania infection within the indigenous population. Furthermore, a previous study [22] had suggested that the high prevalence of ATL in this area was due to the presence of a large number of wild reservoirs and high rates of deforestation. The main species involved in this area was L. braziliensis, in agreement with data presented by a study conducted in 2017 [22, 23], which reported on the presence of L. braziliensis in individuals from an indigenous village in Mato Grosso.

ATL infection consequences for pregnant women and maternal-fetal health are rarely and poorly studied. In the present study, pregnant women represented $0.59 \%$ of all ATL cases in Minas Gerais. This result agrees with those of previous findings $[24,25]$, which identified only 27 pregnant women with ATL among a group of 4200 people with the disease. Morgan et al. [24] reported pregnancy-related complications in patients who delivered preterm or had stillbirth, with a frequency of $10.5 \%$ for each group. The municipality of Januária, located $559 \mathrm{~km}$ from the capital city, was considered as a high transmission site in this study, presenting 11 cases (13.9\% of a total of 79 ) of pregnant women diagnosed 
with ATL and, thus, becoming the main focus for analyzing this variable in Minas Gerais (Fig. 2).

The MCA results showed that the peri-urban zone of infection was related to the municipalities that presented moderate to a high number of ATL cases. These results agree with those described in the manual of ATL surveillance [7] and with those of the survey conducted in 2017 [26], which considered the peri-urban zone an important infection area for the disease. Moreover, the literature suggests that the adaptation of the phlebotomine subfamily and anthropic activities that impact the environment are responsible for ATL transmission in the peri-domestic environment. For example, breeding animals close to households favored vector adaptation to the human domain and modified the ATL transmission cycle [27].

In the correspondence analysis, some associations between disease in pregnant women and children younger than 1-year-old and indigenous/yellow ethnicity was found. This might explain the higher susceptibility of these populations to ATL and can be linked to characteristics related to exposure to the vector and vector adaptation to the peri and/or intra-domestic areas [28].

The results observed for the associations among brown skin, age 4 ( 60 years or older), females, infection in rural areas, and disease confirmation using the clinicalepidemiological criteria are similar to those obtained in other published reports [2]. Furthermore, the present study verified that adult males are the most affected, while children and women are affected to a lesser degree.

Analysis of the control diagram showed that ATL is endemic to Minas Gerais, as the data on disease frequency in this area are similar to the results seen in the past in the absence of epidemics. In addition, we verified that during cold months there was a slight decrease in the occurrence of ATL cases, which demonstrated a correlation between temperature and phlebotomine activity, as described in a study conducted in 2017, which compared the activity of the vector during different seasons [29].

When taking the entire country into account, the average prevalence rate for ATL was approximately 118.9 cases for every 100,000 inhabitants, suggesting that the situation in Minas Gerais was less critical, as it has an average prevalence rate of 66.5 cases for every 100,000 inhabitants. However, the cutoff that determined whether certain locations were at a high risk, is 448.3 cases for every 100,000 inhabitants [11]. In this study, we found that the municipalities highlighted in Table 1 are at a higher risk of leishmaniasis transmission.

\section{Conclusion}

The present study provides a new perspective on ATL as it involved a multivariate analysis using multiple correspondence analysis and used epidemiological and demographic variable data openly available on SINAN and IBGE.
We verified that ATL was endemic to Minas Gerais, especially in municipalities with high transmission rates. The occurrence of the infection in children, pregnant women, and indigenous populations demonstrates the need for the government to implement social policies directed towards these vulnerable groups. Thus, it is essential to fully understand the epidemiology of ATL to implement control measures against this parasite.

ATL is a health priority in certain municipalities of Minas Gerais. Our study evaluated disease epidemiology and discussed the need for public policies to address ATL. Recently, Brazil decentralized its health services; such changes may worsen disease incidence and prevalence in this country, as the country has been struggling economically and lacks human and material resources required for disease control.

Cases of ATL notified through a secondary database can be a limitation for this type of epidemiological study as they can lead to an underestimation of disease prevalence, due to under-reporting, and cause collection bias. Moreover, ecological studies can be susceptible to ecological bias as they do not allow for analysis of individual data.

\section{Abbreviations \\ High: Municipalities with high number of cases; Low: Municipalities with low number of cases; Mode: Municipalities with moderate number of cases; N_Age0: Not age 0 (younger than 1-year-old); N_Age1: Not age 1 (1-14 year- old); N_Age2: Not age 2 (15-19years old); N_Age3: Not age 3 (20-59years old); N_Age4: Not age 4 (60 years old or older); N_Ana: Not illiterate; N_Bla: Not black patients; N_Bro: Not brown patients; N_Cl_ep: Not evaluated using clinical-epidemiological criteria; N_Fem: Not female patients; N_GD: Do not have graduate degree; N_HS: Do not have high school degree; N_Ind: Not Indian patients; N_Per: Not peri urban area; N_Preg: Not pregnant; N_Ru: Not rural area; N_Yel: Not yellow patients; Y_Age0: Age 0 (younger than 1-year-old); Y_Age1: Age 1 (1-14 years old); Y_Age2: Age 2 (15-19 years old); Y_Age3: Age 3 (20-59 years old); Y_Age4: Age 4 (60 years old or older); Y_Ana: Illiterate; Y_Bla: Black patients; Y_Bro: Brown patients; Y_Cl_ep: Evaluated using clinical-epidemiological criteria; Y_Fem: Female patients; Y_GD: Have graduate degree; Y_HS: Have high school degree; Y_Ind: Indian patients; Y_Per: Peri urban area; Y_Preg: Pregnant; $Y \_R u:$ Rural area; Y_Yel: Yellow patients}

\section{Acknowledgments \\ We thank the UFMG Veterinary School for making the epidemiology laboratory available for data analysis.}

\section{Authors' contributions \\ MOKMP, TMO and ANAA conceived the study and drafted the manuscript; TMO, DSB carried the analysis and interpretation of data and drafted the manuscript; PEMP, SAD and MXS critically revised the manuscript for intellectual content. All authors read and approved the final manuscript.}

\section{Funding}

We appreciate the financial support and scholarships provided by Fundação de Amparo à Pesquisa do Estado de Minas Gerais (FAPEMIG) and by Coordenação de Aperfeiçoamento de Pessoal de Nível Superior (CAPES). The financial support did not play any role in the design of the study or collection, analysis, and interpretation of data. 


\section{Availability of data and materials}

All data presented in the study can be accessed in the SINAN and IBGE databases (available at http://datasus.saude.gov.br and http://www.ibge.gov.br, respectively).

\section{Ethics approval and consent to participate}

This study is based on secondary data, and all presented information is ofpublic domain. None of the variables or data used in this study allowed theidentification of individuals. Thus, approval of the study by an Ethical ReviewBoard was not necessary. Ethnicity data is based on the IBGE demographic census, as shown on the website <https:// educa.ibge.gov.br/jovens/conheca-o brasil/populacao/18319-cor-ouraca.html>.

\section{Consent for publication}

Not applicable.

\section{Competing interests}

The authors declare that they have no competing interests.

\section{Author details}

${ }^{1}$ Preventive Veterinary Medicine Department, School of Veterinary, Federal University of Minas Gerais, Belo Horizonte 31270-901, Brazil. ${ }^{2}$ Prefecture of Belo Horizonte, Belo Horizonte, Minas Gerais 31130-908, Brazil. ${ }^{3}$ Parasitology Department, Biological Sciences Institute, Federal University of Minas Gerais, Belo Horizonte 31270-901, Brazil. ${ }^{4}$ Centro Universitário UniDoctum de Teófilo Otoni, Veterinary Medicine Course, Teófilo Otoni, Brazil.

\section{Received: 14 February 2019 Accepted: 6 February 2020}

\section{Published online: 22 February 2020}

\section{References}

1. Alvar J, Vélez ID, Bern C, Herrero M, Desjeux P, Cano J, et al. Leishmaniasis worldwide and global estimates of its incidence. PLoS One. 2012;7(5): e35671. https://doi.org/10.1371/journal.pone.0035671.

2. Gosch CS, Marques CP, Resende BS, Souza JD, Rocha RAD, Lopes DSS, et al. American tegumentary leishmaniasis: epidemiological and molecular characterization of prevalent Leishmania species in the state of Tocantins, Brazil, 2011-2015. Rev Inst Med Trop S Paulo. 2017;59:e91. https://doi.org/10. 1590/s1678-9946201759091.

3. Anversa L, Tiburcio MGS, Richini-Pereira VB, Ramirez LE. Human leishmaniasis in Brazil: a general review. Rev Assoc Med Bras. 2018;64(3): 281-9. https://doi.org/10.1590/1806-9282.64.03.281.

4. Chagas ECD, Silva AS, Fe NF, Ferreira LS, Sampaio VD, Terrazas WCM, et al. Composition of sand fly fauna (Diptera: Psychodidae) and detection of Leishmania DNA (Kinetoplastida: Trypanosomatidae) in different ecotopes from a rural settlement in the Central Amazon. Brazil Parasit Vectors. 2018; 11:180. https://doi.org/10.1186/s13071-018-2743-6.

5. de Souza CF, Brazil RP, Bevilacqua PD, Andrade JD. The phlebotomine sand flies fauna in Parque Estadual do Rio Doce, Minas Gerais. Brazil Parasit Vectors. 2015;8:619. https://doi.org/10.1186/s13071-015-1227-1.

6. Silva J, Queiroz A, Moura I, Sousa RS, Guimaraes LH, Machado PRL, et al. Dynamics of American tegumentary leishmaniasis in a highly endemic region for Leishmania (Viannia) braziliensis infection in Northeast Brazil. PLoS Negl Trop Dis. 2017;11(11):e0006015. https://doi.org/10.1371/journal. pntd.0006015.

7. Brasil. Ministério da Saúde. Secretaria de Vigilância em Saúde. Departamento de Vigilância das Doenças Transmissíveis. Manual de vigilância da leishmaniose tegumentar [recurso eletrônico] / Ministério da Saúde, Secretaria de Vigilância em Saúde, Departamento de Vigilância das Doenças Transmissíveis. - Brasília: Ministério da Saúde, 2017. 189 pp. http:// bvsmssaudegovbr/bvs/publicacoes/manual_vigilancia_leishmaniose_ tegumentarpdf Accessed 19 Jun 2018.

8. Nascimento BWL, Saraiva L, Neto RGT, Meira P, Sanguinette CD, Tonelli $G B$, et al. Study of sand flies (Diptera: Psychodidade) in visceral and cutaneous leishmaniasis areas in central western of Minas Gerais state Brazil. Acta Trop. 2013;125(3):262-8. https://doi.org/10.1016/j.actatropica. 2012.11.005.

9. IBGE - Instituto Brasileiro de Geografia e Estatística. Censo demográfico 2010. Panorama da população. Resultados do universo Available from: https://wwwibgegovbr Accessed 10 May 2018.
10. IEF- Instituto Estadual de Florestas. Características da região do estado de Minas Gerais. Available from: http://www.ief.mg.gov.br/florestas Accessed 19 May 2018.

11. OPAS - Organização Pan-Americana da Saúde - OPAS/OMS. Informe de Leishmanioses. №. 6. 2018. Available from:<http://iris.paho.org/xmlui/ bitstream/handle/123456789/34857/ LeishReport6_por.pdf?sequence=5>. Accessed 23 May 2018.

12. Mingoti SA. Análise de dados através de métodos de estatística multivariada - uma abordagem aplicada. ed. UFMG: Belo Horizonte; 2005. p.257-267.

13. Medronho RA, Werneck GL, Perez MA. Epidemiologia: Distribuição das Doenças no Espaço e no Tempo. In: Medronho RA, Luiz RR, Bloch KV, Werneck GL.editores. São Paulo: Editora Atheneu; 2009. p. 83-102.

14. de Castilho SC, da Silva DF, Stumpp R, Rego FD, Tonelli GB, Tanure A, et al. Comparison of the phlebotomine (Diptera: Psychodidae) fauna of urban, transitional, and wild areas in northern Minas Gerais. Brazil Parasit Vectors. 2015;19(8):428. https://doi.org/10.1186/s13071-0151003-2.

15. Tonelli GB, Tanure A, Rêgo FD, Carvalho GM de L, Simões TC, Andrade Filho JD. Aspects of the ecology of phlebotomine sand flies (Diptera: Psychodidae) in the private natural heritage reserve sanctuary Caraça. PLoS One. 2017;12:e0178628. https://doi.org/10.1371/journal.pone. 0178628.

16. de Souza CF, Quaresma PF, Andrade JD, Bevilacqua PD. Phlebotomine fauna in the urban area of Timoteo, state of Minas Gerais. Brazil Acta Trop. 2014; 134:72-9. https://doi.org/10.1016/j.actatropica.2014.02.019.

17. de Araujo AR, Portela NC, Feitosa APS, da Silva OA, Ximenes RAA, Alves LC, et al. Risk factors associated with American cutaneous Leishmaniasis in an endemic area of Brazil. Rev Inst Med Trop S Paulo. 2016;58:86. https://doi. org/10.1590/s1678-9946201658086.

18. Melchior LAK, Brilhante AF, Chiaravalloti-Neto F. Spatial and temporal distribution of American cutaneous leishmaniasis in acre state. Brazil Infect Dis Poverty. 2017;6(1):99. https://doi.org/10.1186/s40249-017-0311-5.

19. Soares L, Abad-Franch F, Ferraz G. Epidemiology of cutaneous leishmaniasis in Central Amazonia: a comparison of sex-biased incidence among rural settlers and field biologists. Tropical Med Int Health. 2014;19(8):988-95. https://doi.org/10.1111/tmi.12337.

20. Temponi AOD, de Brito MG, Ferraz ML, Diniz SD, Silva MX, da Cunha TN. American tegumentary leishmaniasis: a multivariate analysis of the spatial circuits for production of cases in Minas Gerais state, Brazil, 2007 to 2011. Cad Saude Publica. 2018;34(2):e00165716. https://doi.org/10.1590/0102$311 \times 00165716$.

21. Prefeitura de São João das Missões. Sobre o município. [cited in 11 may 2018]. Available from: http://saojoaodasmissoes.mg.gov.br/site/prefeitura/ nossa-cidade/cultura/ Accessed 11 May 2018.

22. Rego FD, Rugani JMN, Shimabukuro PHF, Tonelli GB, Quaresma PF, Gontijo CMF. Molecular detection of Leishmania in Phlebotomine sand flies (Diptera: Psychodidae) from a cutaneous Leishmaniasis focus at Xakriaba indigenous reserve, Brazil. Plos One. 2015;10(4):e0122038. https://doi.org/10. 1371/journal.pone.0122038.

23. de Lima JTR, Gennari SM, Soares HS, Minervino AHH, Malheiros AF, Marques FS, et al. Serodiagnosis of visceral and cutaneous leishmaniasis in human and canine populations living in indigenous reserves in the Brazilian Amazon region. Ver Soc Bras Med Trop. 2017;50(1):61-6. https://doi.org/10. 1590/0037-8682-0377-2016.

24. Morgan DJ, Guimaraes LH, Machado PRL, D'Oliveira JA, Almeida RP, Lago EL, et al. Cutaneous Leishmaniasis during pregnancy: exuberant lesions and potential fetal complications. Clin Infect Dis. 2007;45(4):478-82. https://doi. org/10.1086/520017.

25. Panagopoulos P, Mitsopoulos V, Papadopoulos A, Theodorou S, Christodoulaki C, Aloupogiannis $\mathrm{K}$, et al. Visceral leishmaniasis during pregnancy: a rare case report from Greece. PLoS Negl Trop Dis. 2017;11(2): e0005134. https://doi.org/10.1371/journal.pntd.0005134.

26. Melo HA, Rossoni DF, Teodoro U. Spatial distribution of cutaneous leishmaniasis in the state of Parana. Brazil Plos One. 2017;12(9):e0185401. https://doi.org/10.1371/journal.pone.0185401.

27. de Avila MM, Brilhante AF, de Souza CF, Bevilacqua PD, EAB G, Brazil RP. Ecology, feeding and natural infection by Leishmania spp. of phlebotomine sand flies in an area of high incidence of American tegumentary leishmaniasis in the municipality of Rio Branco, Acre, Brazil. Parasit Vectors. 2018;11(1):64. https://doi.org/10.1186/s13071-018-2641-y. 
28. Sampaio RNR, Gonçalves MC, Leite VA, França BV, Santos G, Carvalho MSL, et al. Estudo da transmissão da leishmaniose tegumentar americana no Distrito Federal. Rev Soc Bras Med Trop. 2009;42(6):686-90. https://doi.org/ 10.1590/50037-86822009000600015.

29. Nikonahad A, Khorshidi A, Ghaffari HR, Aval HE, Miri M, Amarloei A, et al. A time series analysis of environmental and metrological factors impact on cutaneous leishmaniasis incidence in an endemic area of Dehloran. Iran Environ Sci Pollut Res Int. 2017;24(16):14117-23.

\section{Publisher's Note}

Springer Nature remains neutral with regard to jurisdictional claims in published maps and institutional affiliations.

Ready to submit your research? Choose BMC and benefit from:

- fast, convenient online submission

- thorough peer review by experienced researchers in your field

- rapid publication on acceptance

- support for research data, including large and complex data types

- gold Open Access which fosters wider collaboration and increased citations

- maximum visibility for your research: over $100 \mathrm{M}$ website views per year

At $\mathrm{BMC}$, research is always in progress.

Learn more biomedcentral.com/submissions 